\title{
Assessment of methods of marking LED sources with the power of equivalent light bulb
}

\author{
P. TABAKA* and P. ROZGA \\ Lodz University of Technology, Institute of Electrical Power Engineering, 18/22 Stefanowskiego St., 90-924 Lodz, Poland
}

\begin{abstract}
This article presents considerations on the assessment of marking LED sources with the power of an equivalent light bulb. This problem was studied both on the basis of calculations and measurements performed. 17 LEDs of different powers and luminous fluxes were tested. Calculations assessing conformity with the declared power showed that an important disadvantage for most of the LED sources results from the method of marking them with the power of an equivalent light bulb from the point of view of the luminous flux emitted. Manufacturers do not do this correctly, misleading the potential user. Meanwhile, measurements performed in different ambient temperatures indicated that for only 4 from among the 13 LED sources studied the given value of the power of an equivalent light bulb may be recognized as in accordance with the actual state of affairs and still with a reservation that specified ambient temperature shall be required. In other cases the values of power quoted are either understated or overstated.
\end{abstract}

Key words: LED, luminous flux, declared power, photometric parameters.

\section{Introduction}

In connection with the introduction within the European Union (EU) of a ban for the use of energy-consuming lighting products under Directive 2005/31/EC [1] and following the timetable set out in Commission Regulation 244/2009 [2], the classic light bulbs were withdrawn from the lighting market. In other words, a period of forced use of alternative light sources such as compact fluorescent lamps or light emitting diodes (LEDs) has commenced. Currently, a strong demand has been observed in the field of LED sources which are commonly accepted as excellent replacements of classic light bulbs. Simultaneously with the development of LED sources, considerable interest has been noticeable also in the literature where studies of lighting and electrical parameters of LEDs have been presented, and LED-based applications have been considered [3-17]. From the point of view of the average consumer, the fact of strong marketing conducted by the manufacturers of LEDs, which focuses only on the advantages of these types of light sources, is also notable. Thus the consumer associates LEDs with modernity, ecology and long durability. Unfortunately, more and more LED sources available in the market are characterized by a level of emitted light (amount of luminous flux generated) which is not consistent with actual status understood by means of the parameters describing a given source. This is caused by the market presence of a large number of products which are not verified by any institution. Household lighting is not usually managed by specialists, and the choice of the light sources is made by the user. This has some justification because the user knows

\footnotetext{
*e-mail: przemyslaw.tabaka@p.lodz.pl

Manuscript submitted 2017-01-13, revised 2017-04-05, initially accepted for publication 2017-04-13, published in December 2017.
}

his/her needs, likes and dislikes. However, in order to achieve the desired lighting effects, a certain knowledge concerning e.g. the luminous flux emitted, which describes quantitative features of the light, is required. The luminous flux determines the total power radiated by the lamp, which causes a visual impression. The higher the luminous flux, the more intensely the light source shines. In order to present how much light is emitted by the light source being an equivalent of the classic light bulb, manufacturers provide two commonly used powers on the package (for example, $10 \mathrm{~W}=100 \mathrm{~W}$ ). The first power describes the nominal power of the light source while the second one informs with which power of a classic light bulb the first power corresponds when it comes to the luminous flux emitted [3-5, 9-11, 14]. Such form of description is of great convenience for the consumer during the decision making process. Unfortunately, information given by the manufacturers raises some doubts. It is possible to come across light sources which, in accordance to the manufacturer's statement, are actually characterized by identical power (for example, $10 \mathrm{~W}$ ) or similar value of luminous flux (810 and $806 \mathrm{~lm}$, respectively). Yet in the second case the power corresponding with the power of an equivalent light bulb is different (100 W and $60 \mathrm{~W}$, respectively). Such observations have induced the interest of authors in the problem of conformity of declared power of an equivalent light bulb with actual power corresponding with a given LED source of specified parameters.

Another aspect on which the authors focused their studies was the ambient temperature which may have an important impact on the operation of LED sources, especially on the value of luminous flux. Most lamps operate in interiors of the so-called room temperature. However, there are many situations when LED sources are installed in closed luminaries, where the work temperature is much higher. On the other hand, they may also be used in places of lower temperatures (basements, gardens and general outside areas). Thus there is a justified need to see 
how ambient temperature may affect a specific power of an equivalent light bulb. The interest in this issue resulted from the fact that the manufacturers give the basic parameters of LED sources only in relation to room temperature and do not relate them to other temperature in which LEDs may operate.

\section{Methodology}

2.1. Experimental techniques. Measurements of electrical and photometric parameters were conducted using a thermal test chamber. This chamber was made of layer boards with polyurethane core of $100 \mathrm{~mm}$ in thickness. In order to keep the temperature at a predetermined level with stabilization of $\pm 1^{\circ} \mathrm{C}$, freon cooler was used and combined with a blocked electrical heating system. The measurement stand is presented schematically in Fig. 1.

Voltage is supplied to the voltage stabilizer (2) by the power switch (1) providing constant rms value of voltage (with $0.1 \%$



Fig. 1. Schematic diagram of the measurement stand: 1 - power switch, 2 - voltage stabilizer, 3 - autotransformer, 4 - voltmeter, 5 tested LED lamp, 6 - integrating sphere, 7 - thermal test chamber, 8 - measuring window, 9 - optical fiber, 10 - luxmeter measuring head, 11 - luxmeter control unit, 12 - external power supply, 13 - PC type computer recording electrical and photometric parameters, $14-\mathrm{PC}$ type computer controlling the thermal test chamber, 15 - test chamber control system accuracy). Voltage is adjusted using an autotransformer (3) to the value of $230 \mathrm{~V}$, which is controlled by means of the voltmeter (4). The tested LED source is placed in the integrating sphere (6), which is located in the thermal test chamber (7). With the use of the measuring window (8), the measured signal (light) is led out from the test chamber by the optical fiber (9) of $12 \mathrm{~mm}$ in diameter. The signal then goes to the luxmeter measuring head (10). During laboratory measurements, as a result of the light emitted, this measuring head sends the electrical signal to the luxmeter control unit (11), which is connected to the computer (13) by means of an external power supply (12). The connection of both the meters (luxmeter L100 and power analyzer Norma 4000) to the PC type computer has been effected using the RS-232C serial transmission link. Communication between the computer and the two meters used is realized as two-way communication, which means that the meters send data but may also be controlled from the level of computer software.

The process of temperature control inside the thermal test chamber was realized using a PLC controller (15) from the PC computer (14). Measurements were conducted for temperatures such as $-20^{\circ} \mathrm{C},-10^{\circ} \mathrm{C}, 0^{\circ} \mathrm{C},+10^{\circ} \mathrm{C},+20^{\circ} \mathrm{C},+30^{\circ} \mathrm{C}$ and $+40^{\circ} \mathrm{C}$. These temperatures were understood as temperatures inside the integrating sphere, and were controlled using the temperature sensors placed inside it.

The measurements were performed separately for the distinctive LED sources and for the above-mentioned temperatures at constant rms voltage equal $230 \mathrm{~V}$. During this process, all the LEDs were installed within the integrating sphere with the handle pointing downwards. Registration was conducted after 60 minutes from the moment of stabilizing inside the integrating sphere of a given temperature. Due to the time-consuming nature of the studies, it was assumed that such a time is enough to stabilize both the electrical and photometric parameters of the LED sources tested.

2.2 LED sources tested. Seventeen LED sources (all presented in Table 1) of different powers and luminous fluxes were analyzed .uring the studies.

Table 1

Basic parameters of the LED sources tested (parameter values come from datasheets)

\begin{tabular}{|r|c|c|c|c|}
\cline { 2 - 5 } \multicolumn{1}{c|}{} & $\boldsymbol{I}[\mathbf{m A} \mathbf{A}$ & $\boldsymbol{P}_{\mathbf{n}}[\mathbf{W}]$ & $\boldsymbol{\Phi}[\mathbf{I m}]$ & $\boldsymbol{P}_{\text {eq }}[\mathbf{W}]$ \\
\hline 1 & $\mathrm{x}$ & 3.5 & 420 & $45 \mathrm{~W}$ \\
\hline 2 & $\mathrm{x}$ & 4 & 400 & $40 \mathrm{~W}$ \\
\hline 3 & $\mathrm{x}$ & 4.6 & 440 & $40 \mathrm{~W}$ \\
\hline 4 & 44 & 5 & 350 & $32 \mathrm{~W}$ \\
\hline 5 & 80 & 5 & 440 & $38 \mathrm{~W}$ \\
\hline 6 & $\mathrm{x}$ & 5 & 500 & $\mathrm{x}$ \\
\hline 7 & $\mathrm{x}$ & 8.5 & 980 & $\mathrm{x}$ \\
\hline 8 & $\mathrm{x}$ & 9 & 806 & $52 \mathrm{~W}$ \\
\hline 9 & 85 & 9 & 806 & $60 \mathrm{~W}$ \\
\hline 10 & $\mathrm{x}$ & 9.5 & 950 & $\mathrm{x}$ \\
\hline
\end{tabular}




\begin{tabular}{|c|c|c|c|c|}
\cline { 2 - 5 } \multicolumn{1}{c|}{} & $\boldsymbol{I}[\mathbf{m A}]$ & $\boldsymbol{P}_{\mathbf{n}}[\mathbf{W}]$ & $\boldsymbol{\Phi}[\mathbf{I m}]$ & $\boldsymbol{P}_{\mathbf{e q}}[\mathbf{W}]$ \\
\hline 11 & $\mathrm{x}$ & 10 & 1055 & $\mathrm{x}$ \\
\hline 12 & 78 & 13 & 1200 & $75 \mathrm{~W}$ \\
\hline 13 & $\mathrm{x}$ & 13.5 & 1200 & $100 \mathrm{~W}$ \\
\hline 14 & $\mathrm{x}$ & 13.5 & 1350 & $100 \mathrm{~W}$ \\
\hline 15 & 105 & 15 & 1350 & $150 \mathrm{~W}$ \\
\hline 16 & 180 & 20 & 1520 & $100 \mathrm{~W}$ \\
\hline 17 & 180 & 20 & 1520 & $100 \mathrm{~W}$ \\
\hline
\end{tabular}

$\mathrm{x}$ - no information

In order to avoid being accused of advertising the manufacturers or distributors of LED lamps tested, the manufacturers' names were ignored. All the sources were equipped with an E27 handle and earmarked for feeding from a network with voltage frequency of $50 \mathrm{~Hz}$. Each of the sources co-operated with an electronic supply system. The basic parameters of the lamps tested listed in Table 1 are current $(I)$ and nominal $\left(P_{\mathrm{n}}\right)$ power of the LED source, luminous flux $(\Phi)$ and declared power of an equivalent light bulb $\left(P_{\mathrm{eq}}\right)$, respectively. The sources were marked by symbols from 1 to 17 , which correspond with numbers from Table 1. The lamps were arranged from the lowest to the highest nominal power.

\section{Results}

3.1. Assessment of conformity with the power declared. For the lamps in relation to which the manufacturers gave the value of luminous flux and declared power of an equivalent light bulb,

Table 2

Required value of luminous flux for non-directional household lamps in relation to the power of classic light bulbs

\begin{tabular}{|c|c|c|c|}
\hline \multirow{2}{*}{$\begin{array}{c}\text { Nominal power } \\
\text { of "classic" } \\
\text { light bulb }\end{array}$} & \multicolumn{3}{|c|}{ Luminous flux } \\
\cline { 2 - 4 } & Light bulb & \multicolumn{2}{|c|}{ LED source } \\
\hline $15 \mathrm{~W}$ & 110 & 136 & 123.6 \\
\hline $25 \mathrm{~W}$ & 220 & 249 & 113.2 \\
\hline $40 \mathrm{~W}$ & 415 & 470 & 113.3 \\
\hline $60 \mathrm{~W}$ & 710 & 806 & 113.5 \\
\hline $75 \mathrm{~W}$ & 930 & 1055 & 113.4 \\
\hline $100 \mathrm{~W}$ & 1340 & 1521 & 113.5 \\
\hline $150 \mathrm{~W}$ & 2160 & 2452 & 113.5 \\
\hline $200 \mathrm{~W}$ & 3000 & 3452 & 115.1 \\
\hline $300 \mathrm{~W}$ & 4850 & \multicolumn{3}{|c|}{$\mathrm{x}$} \\
\hline $500 \mathrm{~W}$ & 8300 & \multicolumn{3}{|c|}{$\mathrm{X}]$} \\
\hline
\end{tabular}

1) the values of luminous flux come from information provided on the light bulb packages with a transparent bulb inside, produced by one of the local manufacturers;

${ }^{2)}$ the values of luminous flux come from the table provided in [2]; $\mathrm{x}-$ not defined in [2]. the calculations were performed in order to verify dependability of the information provided on the packages. These calculations were performed on the basis of data about the declared luminous flux using also data included in Table 2, which presents the required value of luminous flux for non-directional household lamps in relation to the power of classic light bulbs.

An additional column is quoted in this Table, providing relative values of luminous flux. This allows for taking into account the percentage differences between luminous flux of a classic light bulb and its equivalent LED replacement. The actual values of power for the distinctive replacements were determined as linear interpolation based on the value of luminous flux quoted by the manufacturer and the guidelines provided in [2]. The latter are set in Table 2.

Regulation [2] sets the required values of luminous flux corresponding to the normalized series of power of lamps from the range of between 15 and $200 \mathrm{~W}$ for the distinctive replacements of classic light bulbs. In the case of light bulbs of higher powers $(300 \mathrm{~W}$ or $500 \mathrm{~W})$, the value of luminous flux was not specified for the equivalent replacements. This is probably caused by the limited use of these powers in households. The declared power of the equivalent light bulb for the intermediate values of luminous flux (not presented in Table 2) was calculated as linear interpolation of two neighboring values. Then, in accordance with the guideline included in [2], the values of power obtained should be rounded to $1 \mathrm{~W}$. The results of the calculations made in this field are presented in Table 3.

Table 3

Declared and calculated values of distinctive quantities characterizing the replacements of classic light bulbs

\begin{tabular}{|c|c|c|c|c|c|c|}
\hline No. & 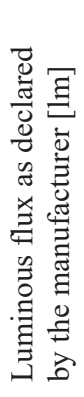 & 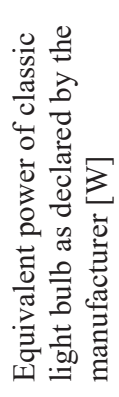 & 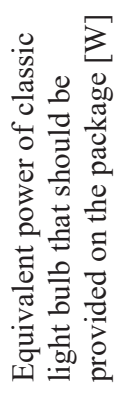 & 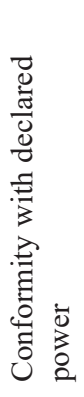 & 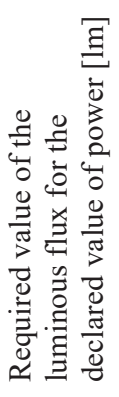 &  \\
\hline 1 & 420 & 45 & 37 & No & 554 & $24.19 \%$ \\
\hline 2 & 400 & 40 & 35 & No & 470 & $14.89 \%$ \\
\hline 3 & 440 & 40 & 38 & No & 470 & $6.38 \%$ \\
\hline 4 & 350 & 32 & 32 & Yes & 352 & $0.57 \%$ \\
\hline 5 & 440 & 38 & 38 & Yes & 441 & $0.23 \%$ \\
\hline 6 & 500 & $\mathrm{x}$ & - & - & - & - \\
\hline 7 & 980 & $\mathrm{x}$ & - & - & - & - \\
\hline 8 & 806 & 52 & 60 & No & 672 & $-19.94 \%$ \\
\hline 9 & 806 & 60 & 60 & Yes & 806 & $0.00 \%$ \\
\hline 10 & 950 & $\mathrm{x}$ & - & - & - & - \\
\hline 11 & 1055 & $\mathrm{x}$ & - & - & - & - \\
\hline 12 & 1200 & 75 & 83 & No & 1055 & $-13.74 \%$ \\
\hline
\end{tabular}




\begin{tabular}{|c|c|c|c|c|c|c|}
\hline No. &  & 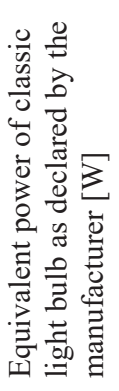 &  & 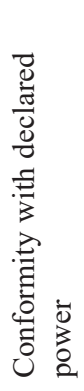 & 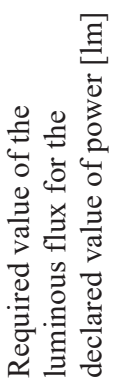 & 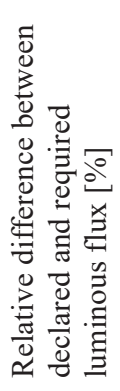 \\
\hline 13 & 1200 & 100 & 83 & No & 1521 & $21.10 \%$ \\
\hline 14 & 1350 & 100 & 91 & No & 1521 & $11.24 \%$ \\
\hline 15 & 1350 & 150 & 91 & No & 2452 & $44.94 \%$ \\
\hline 16 & 1520 & 100 & 100 & Yes & 1521 & $0.07 \%$ \\
\hline 17 & 1520 & 100 & 100 & Yes & 1521 & $0.07 \%$ \\
\hline
\end{tabular}

From Table 3 we can notice that for 8 from among the 13 cases for which the calculation of the power of an equivalent light bulb was possible, non-conformity was determined. The greatest discrepancy is noted for the LED source with nominal power of $15 \mathrm{~W}$ (marked as 15 in the Table), for which the value of an equivalent light bulb is overvalued as $59 \mathrm{~W}$. The manufacturer classified this lamp as a lamp with luminous flux equal of $1350 \mathrm{~lm}$ and the equivalent power of the classic light bulb of $150 \mathrm{~W}$. In accordance with the requirements described in [2], in order for a LED source to be treated as the replacement of a traditional light bulb, it should have the luminous flux of $2452 \mathrm{~lm}$. In the case of the above-mentioned lamp, this means that to conform to the information about the declared power of an equivalent light bulb, the luminous flux of the LED source of $15 \mathrm{~W}$ in power should be about $81 \%$ higher. For this reason, taking into account that similar observations were made also for other LED sources from Table 3, the authors decided to perform additional calculations which could be helpful in assessment of LED sources with incorrect marking. Thus, on the basis of the manufacturers' suggestions in terms of declared power of an equivalent light bulb (also in the way of linear interpolation), corresponding luminous flux was calculated. In all the cases in which the difference between the luminous flux declared and calculated from the declared power exceeded $10 \%$, the result of verification was assessed as negative. Unfortunately, the results obtained were also unsatisfactory. 7 from among 13 of the lamps (i.e. circa $54 \%$ ) did not fulfill the criteria established by the authors in terms of correct marking of the lamps.

The above assessment has a form of theoretical considerations which were aimed at indicating the problem of incorrect marking of the lamps by equivalent power of a classic light bulb. In other words - what were the criteria for determining the power? The results of verification, presented in the abovequoted Table 3, are also hardly optimistic both in the case of column 7 and 5 of this Table. Only 5 from among the 13 lamps (i.e. circa $38 \%$ ) fulfill the criteria in the field of correct marking of the lamp with the power of an equivalent classic light bulb.

In the next step, in relation to individual LED sources, using the integrating sphere, measurements of the luminous flux were performed based on the method described in [18]. As mentioned above, during the measurements the light sources were placed in a position of the handle pointing downwards. The temperature during the measurements was set to $20^{\circ} \mathrm{C} \pm 1^{\circ} \mathrm{C}$. The integrating sphere and the LED sources tested were put in the climate chamber. Registration of luminous flux started just after supplying the LED source with stabilized voltage of $230 \mathrm{~V}$ and then continued through the period of 2 hours. The results of the measurements (in relative values) for three selected LED sources are presented graphically in Fig. 2. The limitation of the data results from the fact that a higher number of examples might limit readability of the figure.

The characteristic feature of all LED sources tested is that just after supplying the voltage they reach maximum luminous flux, which is a feature particularly underlined by the manufac-

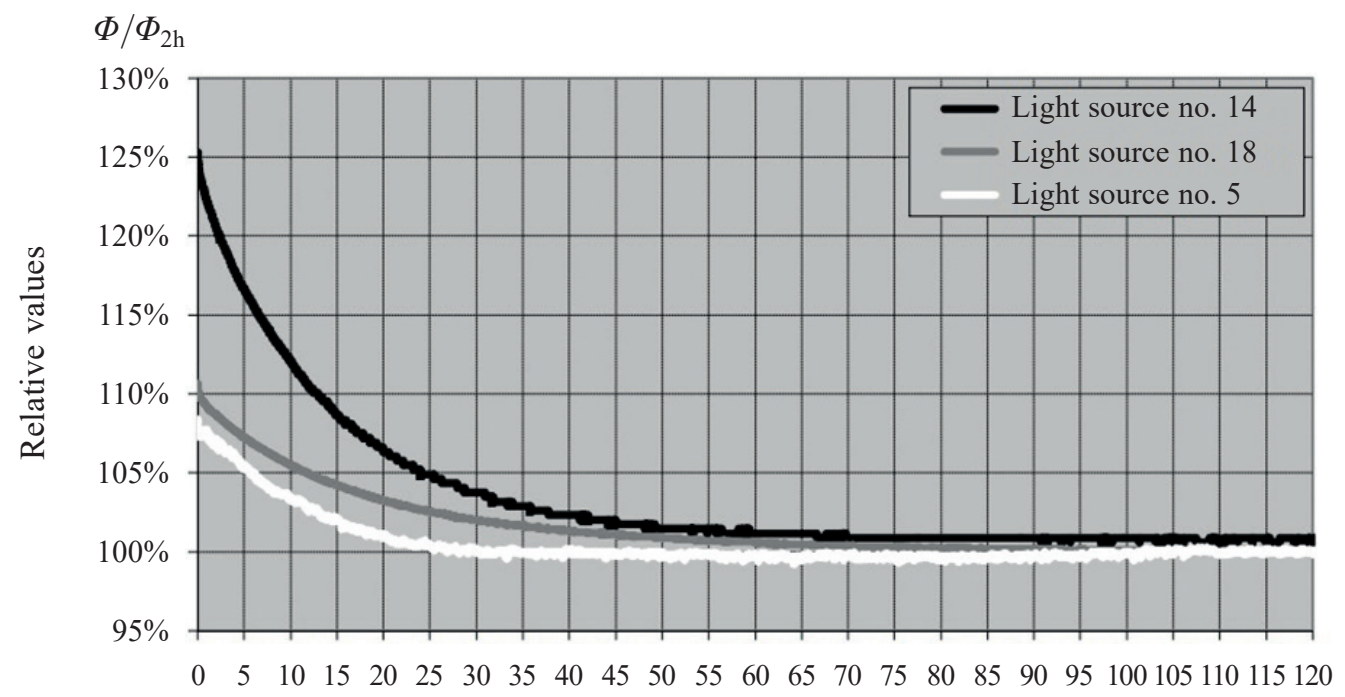

Fig. 2. Change of luminous flux in time for selected LED sources 
Table 4

Comparison of declared and measured luminous flux values

\begin{tabular}{|r|r|r|r|}
\hline No. & $\Phi_{0 \mathrm{~h}} / \Phi_{\mathrm{d}}$ & $\Phi_{1 \mathrm{~h}} / \Phi_{\mathrm{d}}$ & $\Phi_{2 \mathrm{~h}} / \Phi_{\mathrm{d}}$ \\
\hline 1 & $93.6 \%$ & $\mathbf{8 2 . 3 \%}$ & $81.5 \%$ \\
\hline 2 & $98.3 \%$ & $\mathbf{8 6 . 4 \%}$ & $85.6 \%$ \\
\hline 3 & $100.2 \%$ & $90.8 \%$ & $90.0 \%$ \\
\hline 4 & $121.6 \%$ & $\mathbf{1 1 2 . 2 \%}$ & $112.0 \%$ \\
\hline 5 & $105.2 \%$ & $97.0 \%$ & $96.7 \%$ \\
\hline 6 & $87.7 \%$ & $\mathbf{7 7 . 4 \%}$ & $76.9 \%$ \\
\hline 7 & $84.5 \%$ & $\mathbf{7 5 . 8 \%}$ & $75.8 \%$ \\
\hline 8 & $66.2 \%$ & $\mathbf{5 7 . 2 \%}$ & $57.2 \%$ \\
\hline 9 & $105.9 \%$ & $94.1 \%$ & $94.1 \%$ \\
\hline 10 & $131.3 \%$ & $\mathbf{1 1 0 . 5} \%$ & $110.1 \%$ \\
\hline 11 & $105.2 \%$ & $93.4 \%$ & $92.8 \%$ \\
\hline 12 & $118.6 \%$ & $109.9 \%$ & $109.3 \%$ \\
\hline 13 & $102.9 \%$ & $\mathbf{8 7 . 3 \%}$ & $87.0 \%$ \\
\hline 14 & $101.7 \%$ & $\mathbf{8 2 . 1 \%}$ & $81.7 \%$ \\
\hline 15 & $90.0 \%$ & $\mathbf{7 7 . 1 \%}$ & $77.1 \%$ \\
\hline 16 & $151.2 \%$ & $\mathbf{1 2 3 . 6 \%}$ & $123.2 \%$ \\
\hline 17 & $134.6 \%$ & $\mathbf{1 1 1 . 8 \%}$ & $111.6 \%$ \\
\hline
\end{tabular}

turers. However it is important to remember that with increase of the $\mathrm{p}$-n connector temperature (at constant ambient temperature) the luminous flux will decrease. It is in fact most visible in the first several/dozen minutes of operation.

In Table 4 the measured values of luminous flux for distinctive times of operation of the lamp (just after switching on $-\Phi_{0 \mathrm{~h}}$, after one hour $-\Phi_{1 \mathrm{~h}}$, and after two hours $-\Phi_{2 \mathrm{~h}}$ ) are presented. The small differences (below $1 \%$ ) between the values of the luminous flux $\Phi_{1 \mathrm{~h}}$ and $\Phi_{2 \mathrm{~h}}$ may allow to conclude that the period of one hour is enough to obtain thermal stabilization of the given light source and, consequently, its luminous flux. Therefore at verification of the luminous flux declared by the manufacturer the values of $\Phi_{1 \mathrm{~h}}$ were used. As before, the result of verification was recognized as negative when the difference between the declared value of luminous flux and the value determined on the basis of the measurements was higher than $10 \%$. These values were marked by bold fonts in the table. Among the 17 lamps tested, 12 did not fulfill the criteria assumed.

On the basis of general analysis of the values presented in Table 4, the division of LEDs into two groups may be performed. The first group (more numerous) consists of these light sources which are characterized by luminous flux lower than the declared value, while the second group includes the lamps of measured luminous flux higher than the declared value. Because measurements are time-consuming, the data from Table 1 relate only to individual LED sources. To make an objective assessment of these sources from the point of view of emitted luminous flux, studies should be carried out on a more numerous sample of randomly chosen sources of the same power provided by the same manufacturer. Regulation [2], when describing the procedure of verification for LED sources, indicates 20 units of the same type. Results obtained this way would be more reliable, however the experience of the authors allows to conclude that the discrepancies should not be significantly different.

\subsection{Impact of ambient temperature on luminous flux and} power of equivalent light bulb. A serious drawback of LED sources is the dependence of luminous flux on the temperature in which a semiconductor connector operates $[3-5,10,12,17$, 19-21]. Generally, luminous flux decreases when temperature increases. While in the case of individual LED sources (mainly manufactured by renowned manufacturers) the characteristics of the luminous flux drop versus temperature increase are available from datasheets, for the replacements of classic light bulbs made in the LED technology finding out about such characteristics is practically impossible. It is worth noting that a single light emitting diode is currently still only a low-streaming light source, so in practice, the designs of replacements of traditional light bulbs in LED technology need to duplicate the elementary LED sources. In other words, in order to multiply luminous flux of a single LED source. a group of from a few to tens of identical LEDs placed on one common area is used. The shining structure thus created is named a LED matrix. Additionally, the manufacturers equip the light sources with an opal shade shaped in a hemisphere, which acts as a secondary optical system. In order to cause better heat removal from the LED matrix, it is installed on the surface of a radiator. An example of a typical construction of the LED source being a replacement of the light bulb is presented in Fig. 3. (a)

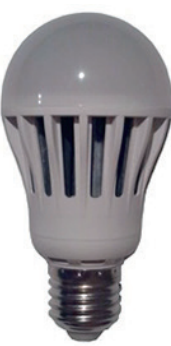

(b)

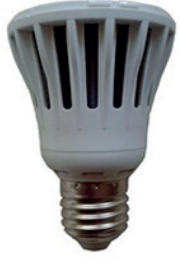

(c)

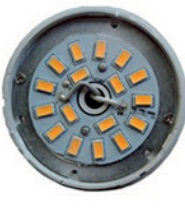

(d)

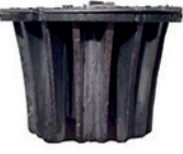

Fig. 3. Typical construction of a LED source used as a replacement of the light bulb: a) complete LED source, b) LED source without the opal shade - side view, c) LED source without the opal shade - top view (LED matrix), d) radiator with the LED matrix located on the top

In the studies presented for each of the LED sources tested, the relative changes of luminous flux versus ambient temperature were registered. These changes are presented in Fig. 4 for three selected cases. Due to the large amount of data which could reduce the clarity of the figure, these light sources were 


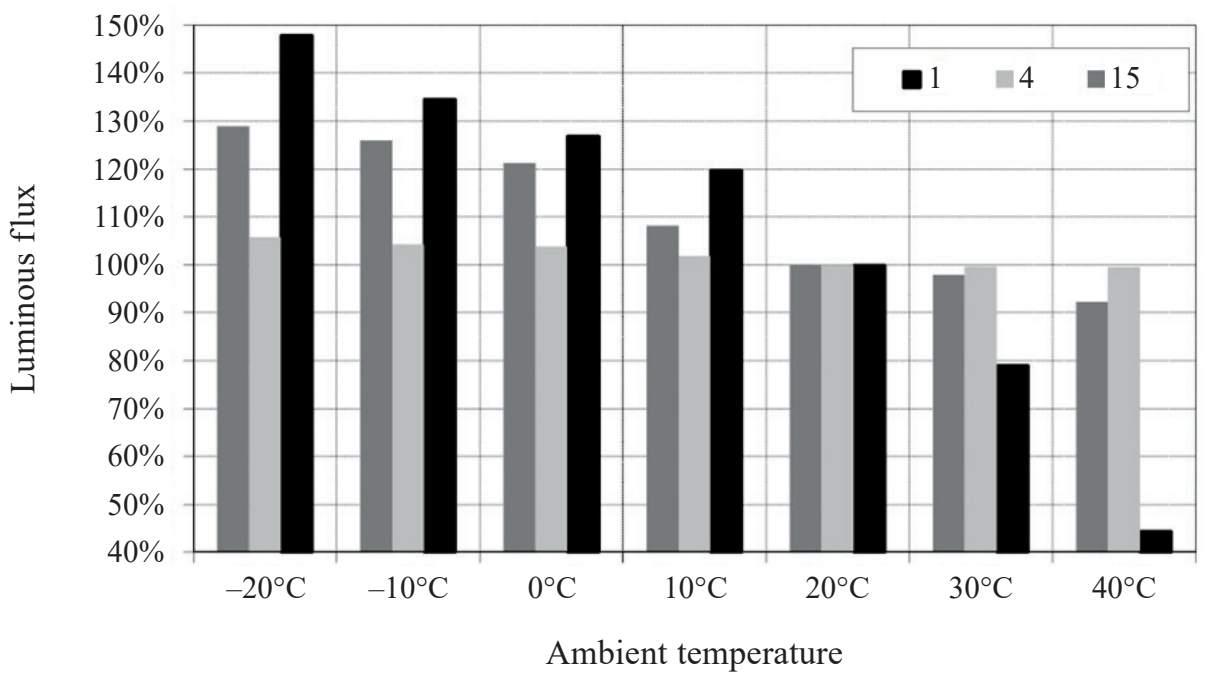

Fig. 4. Change of luminous flux with ambient temperature for selected LED sources

selected as the changes of luminous flux observed for them were the largest, the smallest and intermediate, respectively. The so-called room temperature of $20^{\circ} \mathrm{C}$ was treated as the reference value of temperature $[3-5,17]$.

Based on the knowledge about the relative changes of luminous flux and the absolute value in the temperature of $20^{\circ} \mathrm{C}$, luminous flux reached by individual LED lamps under

Table 5

Declared $\left(P_{\text {dec }}\right)$ and calculated $\left(P_{\text {cal }}\right)$ power of an equivalent light bulb of LED sources tested for different ambient temperatures

\begin{tabular}{|c|c|c|c|c|c|c|c|c|}
\hline \multirow{3}{*}{ No. } & \multirow{3}{*}{$\mathrm{P}_{\mathrm{dec}}[\mathrm{W}]$} & \multicolumn{7}{|c|}{$P_{\text {cal }}[\mathrm{W}]$} \\
\hline & & \multicolumn{7}{|c|}{ Ambient temperature $\left[{ }^{\circ} \mathrm{C}\right]$} \\
\hline & & -20 & -10 & 0 & 10 & 20 & 30 & 40 \\
\hline 1 & 45 & 42 & 40 & 38 & 36 & 31 & 27 & 17 \\
\hline 2 & 40 & 39 & 38 & 35 & 33 & 31 & 30 & 29 \\
\hline 3 & 40 & 37 & 36 & 36 & 36 & 35 & 35 & 33 \\
\hline 4 & 32 & 36 & 36 & 36 & 35 & 35 & 35 & 35 \\
\hline 5 & 38 & 45 & 42 & 40 & 38 & 37 & 35 & 35 \\
\hline 6 & $x$ & 38 & 37 & 36 & 36 & 34 & 34 & 33 \\
\hline 7 & $\mathrm{x}$ & 68 & 66 & 64 & 61 & 56 & 53 & 49 \\
\hline 8 & 52 & 39 & 38 & 37 & 37 & 35 & 34 & 34 \\
\hline 9 & 60 & 65 & 63 & 59 & 58 & 57 & 50 & 44 \\
\hline 10 & $\mathrm{x}$ & 77 & 75 & 72 & 70 & 65 & 60 & 55 \\
\hline 11 & $\mathrm{x}$ & 75 & 73 & 69 & 67 & 65 & 61 & 58 \\
\hline 12 & 75 & 88 & 87 & 86 & 83 & 80 & 78 & 78 \\
\hline 13 & 100 & 91 & 88 & 84 & 80 & 74 & 69 & 61 \\
\hline 14 & 100 & 83 & 79 & 75 & 72 & 70 & 68 & 66 \\
\hline 15 & 150 & 92 & 89 & 86 & 79 & 74 & 71 & 69 \\
\hline 16 & 100 & 145 & 143 & 137 & 129 & 119 & 106 & 92 \\
\hline 17 & 100 & 138 & 134 & 126 & 118 & 109 & 102 & 90 \\
\hline
\end{tabular}

$\mathrm{x}-$ no information the different ambient temperatures was calculated. These data were used for calculation (in accordance with the guidelines described in [2]) of the power of an equivalent light bulb. The results of these calculations are presented in Table 5. The cells for which the calculated powers, constituting information about the light intensity of a given lamp, are lower than the power given by the manufacturer are marked by gray filling.

In the case of 7 light sources (out of 13 for which the manufacturer determined the power of an equivalent light bulb) for any of the ambient temperatures the calculated value of the power does not reach the value quoted by the manufacturer. However in the case of 4 LED sources the required value of luminous flux at which the lamps may be treated as substitutes for classic light bulbs was obtained for the ambient temperature specified. For the LED source marked by No. 5 this temperature equals $10^{\circ} \mathrm{C}$, for source No. 9 it is below $0^{\circ} \mathrm{C}$, and for sources No. 16 and 17 it stands between 30 and $40^{\circ} \mathrm{C}$.

\section{Discussion and conclusions}

The last two decades have been marked by the dynamic development of light sources. Increasingly efficient light sources have been implemented while older proposals, developed in the $20^{\text {th }}$ century have been withdrawn. An excellent example in this field is the modernization of lighting in households, focused on replacement of light bulbs or fluorescent lamps with LED sources, which is a very fast process. The main reason for this is the need of minimization of energy consumption for lighting and thus decreasing the costs of electrical energy.

Analyzing the results obtained by the authors on the basis of the calculations, it may be stated that a significant disadvantage of most LED sources is the method of marking them with the power of the equivalent light bulb when considering marking from the point of view of luminous flux emitted. The manufacturers do not do this correctly thus misleading the potential user. So the question arises whether the light sources should 
be tested in accredited laboratories in order to verify the data provided by the manufacturers or distributors. In such a case, the parameters confirmed by the laboratory would have to be quoted on the package and enclosure, giving the customers assurance about the data characterizing the LED sources. Manufacturers and distributors of LEDs would be responsible for the tests before putting their products on the market. However the necessity of testing LED sources in accredited laboratories is not easy to enforce or to impose onto manufacturers because both the manufacturers and distributors are not required to do so in accordance with the applicable law. None of the legal acts available in the territory of the European Union [22, 23] or local regulations include information about the necessity of performing measurements in an accredited laboratory. In the authors' opinion, such regulations should be introduced which would contribute to prevention against misleading the consumer while simultaneously forcing clarity and reliability in the description of product properties.

After analyzing the measured values of luminous flux taking into account the different ambient temperatures of operation of the LED sources tested, the conclusions are not very optimistic, either. Only for 4 from among 13 LED sources the given value of the power of an equivalent light bulb may be recognized as reflecting the actual state of affairs but still with the reservation that it will only apply at a specified ambient temperature. In other cases the values of power quoted are either understated or overstated. This generates significant doubts concerning the marking the LED lamps with the power of an equivalent light bulb. Due to the long time of the measurements in relation to individual light sources, the results presented in this paper concern only randomly chosen single units from the group of the given type of lamps. Perhaps the results obtained for a larger number of samples would be more optimistic. However the fact remains that with change in the ambient temperature luminous flux emitted by the LED source changes, too, which causes a change in the power of an equivalent light bulb quoted. Hence, in the authors' opinion, in order to provide reliable information about the power of an equivalent light bulb, the range of temperatures for which the power of an equivalent light bulb is actually true should also be provided by the manufacturers. Only with introduction of marking of this kind will the consumer be given a chance to choose a light source according to his/her needs.

Parallelly to the process of withdrawing energy-consuming light sources, the European Union has been promoting the development of modern light sources, especially those based on LED technology. As a result of such promotion, a large number of LED sources of different parameters, construction and prices have appeared in the market. The literature data [9] have indicated that the most important factor in choosing a given light source is the price. This means that the cheapest solutions, which are characterized by lowest quality, remain most popular. The attractive price, together with marketing impact, has a power of quick and easy reaching out to customers. Unfortunately, in many cases purchasing cheaper light sources results in disappointment and dissatisfaction with the amount of light emitted, which may consequently cause an aversion to the new technology. Judging by the results of the studies carried out, such situation may take place in the case of light sources marked as 1, 2, 3, 8, 13, 14 and 15. Yet another situation has been observed, however, in the case of light sources marked as 4 and 12. Although the declared power of an equivalent light bulb did not correspond with the value quoted on the package, the amount of emitted light in a wide range of ambient temperatures (from $-20^{\circ} \mathrm{C}$ to $+40^{\circ} \mathrm{C}$ ) actually proved higher than the declared one.

Thus it may be finally concluded that the influence of ambient temperature on luminous flux of LED lamps is not significant when these lamps are of high quality - in other words, when they are produced by carefully choosing all relevant parameters. The results show that when the lamps fulfill the criteria in terms of marking with the power of an equivalent light bulb (the manufacturer honestly presents the parameters of their product), the properties of the lamps in terms of other features are also on a satisfactory level.

The studies presented herein indicate only a part of a wider issue concerning the replacement of classic light bulbs by modern LED sources. The issues which cannot be ignored are not only quantitative parameters but also the quality of radiation emitted by these modern lamps. Thus problems related to the implementation of LED sources may not be deemed either exhausted or finished at this point.

Acknowledgements. The authors would like to thank the Management Board of "Stowarzyszenie Elektryków Polskich, Oddział Łódzki" for partial sponsorship of the studies presented in this paper within the program supporting young researchers.

\section{REFERENCES}

[1] Commission Directive 2005/31/EC of 29 April 2005 amending Council Directive 84/500/EEC as regards a declaration of compliance and performance criteria of the analytical method for ceramic articles intended to come into contact with foodstuffs.

[2] Commission Regulation (EC) No 244/2009 of 18 March 2009 implementing Directive 2005/32/EC of the European Parliament and of the Council with regard to ecodesign requirements for non-directional household lamps.

[3] K. Wandachowicz and K. Domke, "Measurements of the temperature-dependent changes of the photometrical and electrical parameters of LEDs", Przeglad Elektrotechniczny, 84(8), pp.114-117 (2008).

[4] I. Fryc, "LEDs spectral power distribution under different condition of operating temperature and driving current", Przeglad Elektrotechniczny, 86(10), 187-189 (2010).

[5] K. Domke and C.A. Brebbia, "Light in Engineering, Architecture and the Environment", WITpress, Southampton, Boston (2011).

[6] K.R. Shailesh, C.P. Kurian, and S.G. Kini, "LED lighting reliability from a failure perspective", Proceedings of ICETEEEM 2012, 468-472, Chennai, India, (2012).

[7] L. Jia-Ning, J. Yu, T. Yu-Zhen, and Z. Guo-Yi, "Optical design of adjustable light emitting diode for different lighting requirements", Chin. Phys. B, 21(12), 1-4 (2012).

[8] J. Fan, K-C. Yung, and M. Pecht, "Lifetime estimation of highpower white LED using degradation-data-driven method", IEEE Trans. Device and Mater. Reliab. 12, 470-477 (2012). 
[9] M. Maciejewski and W. Żagan, "The studies on structure of the light sources used in housing illumination", (in Polish) Wiadomości Elektrotechniczne, 10, 3-7 (2013).

[10] P. Tabaka and A. Wiśniewski, "Measurements of electric, photometric and colorimetric parameters of LED using at different ambient temperatures", Light and Engineering, 22(1), 48-56 (2014).

[11] R. Dangol, M.S. Islam, M. Hyvärinen, P. Bhushal, M. Puolakka, and L. Halonen, "User acceptance studies for LED office lighting: Preference, naturalness and colourfulness", Lighting Res. Technol. 47(1), 36-53 (2015).

[12] K.R. Shailesh, C.P. Kurian, and S.G. Kini, "Measurement of junction temperature of light-emitting diodes in a luminaire", Lighting Res. Technol., 47(5), 620-632 (2015).

[13] N. Narendran and Y. Gu, "Life of LED-based white light sources", Journal of Display Technology, 1, 167-171 (2015).

[14] M-C Dubois, F. Bisegna, N. Gentile, and E. Tetri, "Retrofitting the electric lighting and daylighting systems to reduce energy use in buildings: a literature review", Energy Research Journal, $6,25-41$ (2015)

[15] K. Sudars, R. Cacurs, I. Homjakovs, and J. Judvaitis, "LEDs based video camera pose estimation", Bull. Pol. Ac.: Tech. 63(4), 897-905 (2015)

[16] Y. Xu, Y. Chang, G. Chen, and H. Lin, "The research on LED supplementary lighting system for plants", Optik, 127 (18), 7193-7201 (2016).
[17] M.B. Yurtseven, S. Mete, and S. Onaygil, "The effects of temperature and driving current on the key parameters of commercially available high-power, white LEDs", Lighting Res. Technol., 48(8), 943-965 (2016).

[18] CIE 84-1989 - The measurement of luminous flux.

[19] Y. Qin, D. Lin, and S.Y. Hui, "A simple method for comparative study on the thermal performance of LEDs and fluorescent lamps", IEEE Trans. Power Electron., 24(7), 1811-1818 (2009).

[20] K. Gorecki and P. Ptak, "The influence of the mounting manner on thermal and optical parameters of power LEDs", Intern. Journal of Microelectr. Comp. Sci., 6(1), 23-28 (2015).

[21] K. Gorecki and P. Ptak, "Modelling LED lamps with thermal phenomena taken into account", 22nd Intern. Workshop on Thermal Investigations of ICs and Systems (THERMINIC), pp. 21-23.09.2016, Budapest, Hungary, 202-207.

[22] Commision Directive 2006/95/EC of the european parliament and of the council of 12 December 2006 on the harmonisation of the laws of member states relating to electrical equipment designed for use within certain voltage limits.

[23] Commision Directive 2014/35/eu of the european parliament and of the council of 26 February 2014 on the harmonisation of the laws of the Member States relating to the making available on the market of electrical equipment designed for use within certain voltage limits. 